\title{
FILOSOFANDO COM GADAMER E PLATÃO: MOVIMENTOS, MOMENTOS E MÉTODO[S] DA DIALÉTICA.
}

\author{
Luiz Rohden \\ Unisinos
}

\begin{abstract}
Resumo: À luz da Carta Sétima de Platão, justificamos o filosofar tramado entre o exercício fenomenológico e hermenêutico sob a égide dos 'elogios à verdadeira filosofia'. Desenvolveremos aqui que ele se efetiva dialeticamente segundo os movimentos descendente [constituída pelo todo da carta; trata-se da vertente dialógico-prática - ética, política] e ascendente [descrita na digressão da carta; trata-se da face inteligível-teórico metafísica]. Conferiremos atenção especial aos cinco momentos [nome, definição, imagem, ciência e 'a coisa mesma'] do itinerário ascendente. Ao final, mostraremos que o método do método dialético é dialético também e efetiva-se tanto entre os dois movimentos quanto entre seus momentos internos o que leva à instituição de uma circularidade espiral ascensional ou de um círculo virtuoso. Com isto mostraremos que o filosofar constitui-se enquanto uma metafísica dialética marcada pela temporalidade e liberdade humana.
\end{abstract}

Palavras-chave: Platão, Gadamer, Dialética, Hermenêutica, Carta Sétima.

\begin{abstract}
Following Plato's Seventh Letter we justify the philosophy plotted between the phenomenological and hermeneutical exercise under auspices of the 'compliments for true philosophy'. We will develop that this philosophy is accomplished dialectically according to descendent movement [formed by the whole letter; it is the dialogical and practical aspects ethics, politics] and ascending movement [described in the tour of the letter; it is the theoretical and intelligible face - metaphysics]. We will grant a special attention to the five moments [name, definition, image, science and 'the thing itself'] of the ascending route. Finally we will show that the method of the dialectic method is also dialectic and is accomplished in these two movements and in its internal moments which leads to the establishment of an ascending spiral circularity or a virtuous circle.
\end{abstract}

Keywords: Plato, Gadamer, Dialectics, Hermeneutics, Seventh Letter. 
[...] só depois de esfregarmos,por assim dizer, uns nos outros, e compararmos nomes, definições, visões e sensações e de discuti-los nesses colóquios amistosos em que perguntas e respostas se formulam sem o menor ressaibo de inveja, é que brilham sobre cada objeto a sabedoria e o entendimento, com a tensão máxima de que for capaz a inteligência humana [Platão, 344b-c].

Caminho: para cima e para baixo, um e o mesmo. Heráclito

Em continuidade à compreensão filosófica da Carta Sétimafilosofando, pois, com Platão e Gadamer - recordamos que justificamos a atualidade da sua re-leitura ao fundamentar o filosofar enquanto um movimento que vai-e-vem entre fenomenologia e hermenêutica (ROHDEN in BOMBASSARO; DALBOSCO; KUIAVA, 2011, p. 87 ss.). Conferimos então um acento especial à leitura platônica da realidade do ponto de vista do que não deveria ser tido na conta de filosofia por parte de Dionísio e da nossa academia. Após ressaltar a importância do exercício fenomenológico efetivado por Platão relativamente ao seu contexto, elaboramos uma reflexão ${ }^{1}$ onde fundamentamos a pertinência da leitura hermenêutica da carta enfatizando o que é e/ou deveria ser considerado como filosofia. Partimos do pressuposto segundo o qual a Carta Sétima de Platão nos apresenta um belíssimo e atual elogio da verdadeira filosofia cuja leitura não só nos é salutar, mas imprescindível para o exercício do autêntico filosofar.

Enquanto que no primeiro texto tecemos uma reflexão entre fenomenologia e hermenêutica segundo a ótica do que não deve ser considerado como filosofia; no segundo, nos ativemos ao que ela deve ser conforme indícios contidos na carta; aqui desenvolveremos o modo de se efetivar o verdadeiro filosofar. Conferiremos atenção à sua face metodológica, isto é, ao método dialético vigente na epístola do ponto de vista dos seus dois movimentos, dos seus momentos internos e o método próprio de ambos à luz da hermenêutica. Nosso intuito, pois, é de filosofar com Gadamer e Platão segundo o seguinte pressuposto: "hermenêutica e

\footnotetext{
${ }_{1}^{1}$ Artigo no prelo da revista Kriterion que será publicado no número 127, janeiro/julho de 2013: "Hermenêutica e[m] resposta ao Elogio da verdadeira filosofia da Carta Sétima de Platão".
} 
dialética representam, de maneira única e privilegiada, o travejamento de um tipo de forma de vida do pensamento que não se descola do mundo e da práxis vivida [...]" (STEIN in HABERMAS, 1987, p. 131).Saliento que três textos acampam-se no quadro mais amplo das minhas pesquisas relativas à leitura hermenêutica de Gadamer em torno dos diálogos de Platão segundo a hipótese de que, a partir, e, com ela, é possível justificar a atualidade de uma metafísica dialética. ${ }^{2}$

Nossa hipótese é de que, com a Carta Sétima, podemos fundamentar e desenvolver o método dialético composto pelo entrelaçamento entre o movimento de subida e de descida dos princípios, isto é, nela podemos rastrear e justificar pertinência da dialética em seu itinerário ascendente e descendente. Vista em seu todo, na carta de Platão delineia-se e se desenrola, de modo vívido e atualíssimo, o método dialético em sua vertente dialógica [prática] que instaura o itinerário descendente [o que foi contemplado, parcialmente, em nossos dois textos mencionados acima] e a face inteligível [teórica] - que é o objeto da nossa reflexão aqui - que pavimenta o movimento de subida e que, tomadas conjuntamente, explicitam-se no aforismo de Heráclito:Caminho: para cima e para baixo, um e o mesmo. (HERÁCLITO, 1980, p. 89).

Diferentemente da leitura corrente, a partir da hermenêutica filosófica, justificamos que o caminho para efetivar a filosofia não se restringe às indicações metodológicas contidas apenas na digressão da Carta Sétima - onde Platão apresenta, de modo muito claro, o método dialético -, mas que, visto em sua totalidade, ele é constituído não apenas pela compreensão, mas também pela 'aplicação' das coisas mais sérias e importantes.Uma das razões para refletir sobre o método em Platão é que nele não podemos separar forma do conteúdo, matéria da sua abordagem; ora, isso está em consonância com nossa concepção de hermenêutica segundo a qual o filosofar deve ser tomado como uma postura [Tugend - intelectual e prática]. O pressuposto disso é que "tanto hermenêutica como dialética trazem em seu ventre a ideia fecunda e inalienável das condições históricas do trabalho do pensamento. Mas afirmam ao mesmo tempo, e por isso mesmo, a impossibilidade de um ponto arquimédico para fundar a reflexão [...]” (STEIN in HABERMAS, 1987, p. 130). Daí porque, com Platão e

\footnotetext{
2 Este texto situa-se no contexto maior das minhas pesquisas, ou seja, compreender e explicitar "Gadamer, intérprete de Platão" do ponto de vista da tradição dialética, metafísica.
} 
Gadamer, é possível fundamentar o filosofar, válido e vital para nossos dias, que se institui enquanto um movimento - da palavra ao conceito e deste àquela - circular virtuoso expresso noutro aforismo heraclitiano:princípio $e$ fim se reúnem na circunferência do círculo (Cf. HERÁCLITO, 1980, p. 121).Nossa abordagem sobre o método dialético será dialética no horizonte da filosofia platônica e gadameriana a partir e em função do nosso tempo.

Considerando que a dialética se articula sobre dois movimentos, a saber, o da subida e o da descida dos princípios, explicitaremos, inicialmente, a face dialógica da dialética [que corresponde ao caminho descendente] e, a seguir - com mais vagar -, nos debruçaremos sobre sua face inteligívelmetafísica [caminho ascendente] levando em conta sempre que ambos são tramados pelo esforço de concretizar a verdadeira filosofia.No interior desse segundo movimento exploraremos seus cincos momentos interconectados entre si. Ao final, justificaremos a vigência dialética não apenas entre o caminho descendente e ascendente, mas entre seus distintos momentos, instituindo uma dialética espiralar ascencional ou circular virtuosa.

\section{Primeiro movimento: a dialética descendente ou dialógica ${ }^{3}$}

“O caminho vai 'da palavra ao conceito' - mas precisamos chegar do conceito à palavra, se quisermos alcançar o outro" (GADAMER in ALMEIDA; FLICKINGER; ROHDEN, 2000, p. 26).

A proposta dialético-dialógica não está descrita objetiva e delimitadamente [como é o caso da dialética ascendente tematizada na digressão], mas revela-se e se instaura na leitura da carta em seu conjunto. É na sua visão conjunta que apreendemos as motivações, as ações e as experiências pessoais/políticas de Platão que constituem seu modo de filosofar, o qual é irredutível a uma fórmula matemática. A partir do todo da carta é possível fundamentar o filosofar enquanto uma trama erigida entre o exercício de ver a realidade em sua maior amplitude possível e a emissão de uma palavra o mais possível eficaz e apropriada a ela. Platão viajou a Siracusa para ensinar o tirano não apenas a ter conhecimentos filosóficos, mas a pô-

${ }^{3}$ Enquanto filosofia prática - hermenêutica, ética, política. 
los em prática; escreveu uma carta filosófica onde teceu elogios à verdadeira filosofia e realizou uma leitura crítica com o escopo de transformar aquela realidade [ética e política]. O conjunto desses indícios constitui a dimensão descendente do método dialético que se realiza pelo paciente e paradoxal esforço de deixar a realidade aparecer em sua integralidade e concomitante propósito de efetivara verdadeira filosofia segundo a lógica do diálogo hermenêutico. Ora, aqui dialética e hermenêutica têm sua intersecção na medida em que

“são a afirmação extrema do significado prático da razão humana, no seu sentido mais forte. Não simplesmente porque esses dois métodos têm a práxis como objeto, mas porque não há práxis no seu sentido pleno sem que pressuponha os horizontes do pensamento dialético e hermenêutico. Filtra-se, portanto, na controvérsia entre dialética e hermenêutica e na discussão sobre dialética e hermenêutica, a afirmação do sentido ético-político do pensamento. É, sem dúvida, esse sentido prático, com sua força expressiva mais radical, que recupera, através de uma controvérsia metodológica, a verdadeira grandeza e dignidade da filosofia" (STEIN in HABERMAS, 1987, p. 131-132).

Em seu conjunto, podemos dizer que a proposta hermenêutica de Gadamer equipara-se, basicamente, à face descendente da dialética platônica. Segundo nossa hipótese, o diálogo hermenêutico, enquanto modelo estrutural tanto de compreensão quanto de 'correção' do real, implica também a efetivação da justiça e da liberdade. Por essa razão, designamos de dialético-dialógico o modo de proceder proposto pela hermenêutica filosófica em complemento crítico àquela dialética sintética cuja meta consiste em culminar numa síntese absoluta e definitiva.

A postura platônica revela e justifica o que compreendemos por dialética dialógica que se instaura sobre alguns traços distintos e complementares entre si lidos na carta. Em primeiro lugar, pela motivação de Platão para escrevê-la, ou seja, de ajudar moços e velhos a compreenderem melhor o que havia sucedido com ele ao procurar efetivar seu projeto filosófico de tornar o mau tirano em um bom tirano [ou filósofo] em Siracusa. Apesar de suas restrições à linguagem escrita - aplicável também à oral - escreveu-a para apontara inesgotabilidade da filosofia frente às 
limitações próprias da sua expressabilidade. Nesse sentido, é inegável que o escrito - dialógico, epistolar de Platão - constitui um caminho excelente, ainda que deficitário,auxiliar à compreensão e à prática da justiça.

Em segundo lugar, o relato pessoal testemunhal escrito das experiências de sua atuação ético-política, configura outro traço essencial da dialética dialógica. O testemunho da sua prática filosófica - com os pequenos êxitos e fracassos do seu ensino filosófico - em suas idas e vindas a Siracusa erigiu uma experiência filosófica. Embora não tenha ocorrido um diálogo filosófico pleno entre Platão e Dionísio - pela falta de compromisso com a coisa mesma e ausência de exigências imprescindíveis por parte dele podemos dizer que houve um ensaio dialógico que foi interrompido.

Em terceiro lugar, o método dialético-dialógico é concebido aqui enquanto exercício de efetivação da 'verdadeira filosofia'. Ele consiste em discernir, na prática, o que não é filosófico sob a ótica dos elogios à verdadeira filosofia apresentados na carta. Há uma circularidade virtuosa, espiralar entre o que é, o que não é e o que deveria ser filosofia.

A dialética descendente tem um escopo prático e, por assim dizer, pragmático, porém jamais se desvencilha da sua face inteligível como nos atesta e adverte o conjunto da carta. A meta da face dialógica consiste em justificar a efetivação de uma proposta ética que culmine no exercício da política regida por leis justas e promotoras da liberdade. Ela se corporifica, metaforicamente, pois, na viagem de volta que o prisioneiro liberto faz à caverna mediante sua prática e seu escrito.

Vejamos indícios estruturais do método dialético descendente expressos em algumas exigências do exercício dialógico. ${ }^{4} \mathrm{O}$ modelo estrutural do diálogo instaura-se sobre as seguintes condições:ele acontece plenamente entre parceiros que comungam dos elogios da verdadeira filosofia; nele se procura um acordo linguístico - mesmo que não se efetive plenamente;os envolvidos nele necessitam ouvir e compreender o que o outro está dizendo; o exercício dialógico possibilita que o outro se manifeste e construam um compromisso com coisa buscada; ele é pautado pela abertura e acolhimento do real, do outro e da palavra 'final' instituída com consciência de que o

\footnotetext{
${ }^{4}$ Sobre o modelo estrutural do diálogo do ponto de vista da hermenêutica gadameriana ver ROHDEN, L. "Hermenêutica filosófica enquanto diálogo, linguagem e ontologia".In: Hermenêutica filosófica. São Leopoldo: Ed. Unisinos, 2003. p. 177-292. Consultar também desdobramento dessa reflexão em meu capítulo de livro ROHDEN, L. "Sobre as condições e as implicações da arte de dialogar".In: RIBAS, M. A. C. et al. (Org.). Filosofia e Ensino: a filosofia na escola. ljuí: Ed. Unijuí, 2005.pp. 195-211.
} 
processo dialógico não se encerra; os parceiros assumem os riscos decorrentes do itinerário trilhado; leva-se a sério as condições espaço-temporais em que o diálogo se efetiva; e por fim, à luz de Platão de Aristóteles, o método dialético-dialógico acontece em clima de amizade filosófica, onde os parceiros do diálogo filosofam em colóquios amistosos, sem ressaibos de inveja em prol da prática justa e livre.

Atrelado e em complemento à face dialógica da dialética correspondente ao esforço fenomenológico-hermenêutico - subjaz e sustenta o viés teorético estampado no seu movimento ascendente. Trata-se da face lógico-teórica inteligível da dialética tecida pelo esforço de elevar o real ao conceito em complemento ao caminho de descida que constitui o exercício ético-político." Embora Gadamer tenha concedido ênfase ao caminho do conceito à palavra - próprio da face dialógico-descendente - precisamos percorrera estrada que vai da palavra ao conceito de modo a justificar o filosofar enquanto um horizonte e itinerário onde a descida e a subida sejam entrelaçadas e tão indistinguíveis quanto o são $o$ início e $o$ fim na circunferência do círculo.

\section{Segundo movimento: a dialética ascendente}

Como consequência de um comércio prolongado e de uma existência dedicada à meditação de tais problemas é que a verdade brota na alma como a luz nascida de uma faísca instantânea, para depois crescer sozinha [341d].

\subsection{Situação e justificação da dialética ascendente}

Faz parte da filosofia de Platão e, portanto, de sua estratégia, não oferecer uma definição cabal sobre temas e menos ainda sobre seu método. Frustra-se, pois, aquele que quiser encontrá-lo condensado em uma fórmula nos seus escritos, pois as "indicações metodológicas encontram-se dispersas por toda a obra de Platão. Elas nem sempre são muito explícitas, a julgar pela diversidade

* Devo esta dica, em parte, às observações e comentários do prof. Carbonari, em discussões sobre o tema em questão. 
dos comentários que suscitaram. Por vezes elas se adaptam estreitamente ao contexto e esclarecem apenas pontos particulares" (GOLDSCHMIDT, 2002, p. 2). Isso se deve à sua estratégia imbricada com sua concepção dinâmica de filosofia - o que se aplica à proposta filosófica de Gadamer.

Apesar das dificuldades para apreender o método dialético, em sua versão ascendente, é possível identificá-lo, com certa segurança, na Carta Sétima. O trecho que contém o método dialético ascendente - o que é por acaso - é precedido pelo primeiro elogio à verdadeira filosofia. Retomamo-la a fim de situar a razão de ser da dialética ascendente [ou, se quisermos, da metafísica dialética] no contexto da carta. Lembremos que, naquela altura da epístola, Platão criticava a postura de Dionísio que "dava-se ares de saber muitas coisas e de dominá-las, principalmente as mais importantes" e "soube que chegara a escrever um tratado acerca das questões aprendidas comigo, que ele se apresentava como um trabalho original" diante do que assim se posicionou:

“[...] de mim, pelo menos, nunca houve nem haverá nenhum escrito sobre semelhante matéria [...] Como consequência de um comércio prolongado e de uma existência dedicada à meditação de tais problemas é que a verdade brota na alma com a luz nascida de uma faísca instantânea, para depois crescer sozinha" [341b-d].

É, pois, nesse horizonte que Platão apresenta o método dialético [ascendente].

Enquanto que a face descendente da dialética constitui o fio condutor de toda Carta Sétima, a dimensão ascendente encontra-se condensada entre as linhas 342a - 345c. Alguns especialistas designaram esse trecho de digressão, outros de excursus. Independentemente da denominação atribuída a ele, o que importa é que não constitui um apêndice externo ao escrito, mas visa corroborar e fundamentar conceitualmente, no conjunto do relato, sua concepção dinâmica de filosofia do ponto de vista metodológico. Comparativamente aos outros textos de Platão, a digressão ou o excursus, parece assumir aqui função similar ao do uso do mito, com a diferença de que se trata de um exemplo claro, sistemático e conceitual.

No trecho em questão, Platão nos apresenta os [cinco] distintos momentos ou etapas ou passos ou, estágios da caminhada dialética. Nele encontramos a estrutura do método dialético ascendente ou teóricometafísico ao indicar o caminho para 'atingir' os princípios supremos 
seguindo determinados passos. Disso se segue que o método dialético não pode ser tomado como algo externo ao processo filosófico, mas compreendese e justifica-se no interior da trama da carta de modo que a teleologia proposta e procurada efetiva-se no seu duplo movimento.

\title{
2.2. Momentos do movimento dialético ascendente
}

De acordo com a Carta Sétima,

\begin{abstract}
“[...] para cada ser há três elementos que nos permitem conhecê-lo; o quarto é o próprio conhecimento, vindo a ser o quinto a coisa conhecida e que verdadeiramente existe. $\mathrm{O}$ primeiro é o nome; o segundo, a definição; o terceiro, a imagem, e o quarto, o conhecimento [...]" [342a-b]..$^{5}$
\end{abstract}

São cinco distintos momentos que compõem a dinâmica da dialética ascendente, sendo que os três primeiros possuem uma afinidade entre si que nos permite justificar a formação de uma unidade epistemológica [quiçá até propedêutica à filosofia] necessária à instituição da ciência e da filosofia. Do ponto de vista hermenêutico, eles corresponderiam ao que designamos de hermenêutica metodológica. ${ }^{6} \mathrm{O}$ quarto e o quinto momentos têm características próprias e encontram-se ecoados, em grande medida, na hermenêutica filosófica.

\subsubsection{Primeiro momento: nome ou palavra [onoma]}

O nome é o primeiro momento da dialética exemplificado pelo círculo: "é o que é dito, que tem esse mesmo nome que agora enunciamos" [342b], que apresenta clara consonância entre uma expressão e uma 'coisa'. O círculo é apenas um exemplo de nome que poderia ser substituído por outro;

\footnotetext{
${ }^{5} \mathrm{~A}$ afirmação de Platão: "há em cada um dos seres", segundo Trindade, na linha da carta, se refere às "condições para o saber [...] enunciadas dizem respeito a todos os seres [...], não apenas a certas naturezas" (Cf. TRINDADE, 2008, p. 91 nota 25), e acerca da passagem: "há três elementos", devemos compreender como "modos" (Cf. TRINDADE, 2008, p. 91 nota 26) momentos, estágios, que nos "permitem possuir conhecimento" e "ciência deles".

${ }^{6}$ Sobre isto ver ROHDEN, L. "Hermenêutica metodológica e hermenêutica filosófica".In: ROHDEN, L. Interfaces da Hermenêutica: método, ética e literatura. Caxias do Sul: Editora UCS, 2008, v.1. p. 35-57.
} 
na carta, encontramos indícios de outros nomes como o bem, o todo, etc. Para Gadamer, a escolha do nome 'círculo' se trata de um excelente exemplo

\begin{abstract}
"Simplesmente porque não se requer nenhum conhecimento prévio da doutrina das ideias ou da dialética dos conceitos para ver que um círculo é algo diferente de coisas circulares que nós chamamos de redondas, curvas, ovais [...] E é claro para nós também que a figura que representamos para ilustrar uma relação matemática visualmente não é a relação matemática ela mesma, e mais claro ainda é que os objetos circulares na natureza não devem ser confundidos com o círculo da matemática. Ele não exige, sobretudo, esforço para compreender o sentido de 'verdadeiro círculo' sobre o qual Platão trata aqui... Um verdadeiro círculo é obviamente algo diferente de tudo isso" (GADAMER, 1970, p. 96).
\end{abstract}

Sabemos da proximidade entre geometria, matemática e filosofia por sua feição inteligível [do real]; entes matemáticos nos permitem visualizar, com certa facilidade, o entrelaçamento entre o sensível e suprassensível. Além disso, mesmo que saibamos o que é o nome círculo, sabemos também que ele não é 'o' círculo.

\title{
2.2.2. Segundo momento: Definição, explanação ou determinação conceitual [logos]
}

A definição é o segundo elemento ou momento de conhecimento no processo dialético. Ela é "composta de nomes e de verbos: aquilo que mantém das extremidades ao meio igual distância em toda parte. A definição valeria para o mesmo que tenha esse nome 'redondo e circular e círculo’” [342b]. A definição de círculo

\footnotetext{
“pertence à categoria dos construtos matemáticos que constituem uma espécie de mundo intermediário entre o sensitivoperceptivo e o inteligível [...] tais entidades matemáticas como o círculo são especialmente adequadas para ilustrar a transição ao pensamento puro o qual, na opinião de Platão é o caminho ao conhecimento verdadeiro e que determina a ‘virada' para a Idéia” (GADAMER, 1970, p. 96-97).
} 
Além disso, a escolha dessa definição, por parte de Platão, "tem uma função propedêutica em relação ao pensamento filosófico" e, a exemplo de outras entidades matemáticas, elas contribuem para exercitar a "visão de alguém para aquilo que é o pensamento puro. Elas como que elevam a alma ao nível do puro pensar no qual elas se afastam de tudo que é encontrado na experiência sensitiva ou em conversações onde são trocadas meras opiniões” (GADAMER, 1970, p. 97). Enfim, "o círculo demonstra que alguém não pode comunicar seu conhecimento a menos que alguém conheça um nome para ele e seja capaz de explicar a palavra que alguém nomeia pelo significado de uma determinação conceitual” (GADAMER, 1970, p. 97).

\subsubsection{Terceiro momento: Imagem, aparência, imagem ilustrativa, exemplo, figura [eidolon]}

O terceiro momento da dialética é a imagem exemplificada pelo círculo: "é o que é desenhado e o que é apagado, o que é torneado e o que se perde. Mas o círculo em si, o mesmo em relação com tudo isso, em nada é afetado, porque é diferente deles" (342c).O momento imagético consiste no conhecimento que produz ilustrações ou cria exemplos para falar de um dado objeto; no caso, tanto o desenho ou a representação de determinado objeto podem ser destruídos, mas o círculo ele mesmo não pode ser destruído (GADAMER, 1970, p. 98).

Podemos dizer que os três primeiros estágios formam, conjuntamente, uma unidade propedêutica, necessária e partícipe dos dois próximos momentos. Eles são como a escada usada para subir aos princípios, necessários para constituição do saber, da intelecção [=insight $]$, mas não instituem ainda, eles mesmos, a coisa mesma procurada. Poderíamos dizer que os três momentos constituem o viés analítico, genealógico, na medida em que têm por escopo apresentar, com a maior clareza possível, as qualidades das coisas nomeando-as, definindo-as e representando-as imageticamente. Em outros termos, os três primeiros momentos configuram a etapa epistemológica ou cognitiva do processo dialético que está na base e institui o polo ontológico ou intuitivo ou sapiencial.

\subsubsection{Quarto momento: o saber, a inteligência e a opinião verdadeira}

Nas palavras de Platão, 
"o quarto é o saber, a inteligência e a opinião verdadeira sobre ele. Ora, essa unidade deve ser posta não em sons, nem em formas de corpos, mas deve ser presente nas almas; o ser destes é manifestamente diferente da natureza do próprio círculo e dos três elementos ditos antes. Desses, o que mais se aproxima por parentesco e semelhança é a inteligência, avizinhada do quinto elemento; os outros se afastam mais" (342c-d).

Com relação à primeira das três caracterizações do quarto momento, as traduções divergem: Carlos A. Nunes empregou o termo conhecimento, Victor Goldschmit traduziu-o por ciência, H-G. Gadamer designou-o como o conhecimento mesmo ${ }^{7}$; quanto ao segundo todos usam o termo inteligência; e há unanimidade entre eles quanto ao emprego da expressão opinião verdadeira.

De acordo com Gadamer, o que acontece nesse momento, e que deve ser acentuado, é que

$$
\begin{aligned}
& \text { “a apreensão de um teorema matemático em nosso } \\
& \text { pensamento não é independente do nosso intelecto [...] como } \\
& \text { qualquer outro pensamento, ele toma parte no vir-a-ser e passa } \\
& \text { a um ser outro que ele mesmo. Diferentemente da coisa } \\
& \text { mesma, a ciência ou conhecimento na alma não se dá fora do } \\
& \text { tempo"(GADAMER, 1970, p. 99). }
\end{aligned}
$$

Daí porque a afirmação deve estar presente na alma enquanto próprio do saber, nas palavras de Trindade, "é aqui dado como um estado que a alma atinge, não como um processo discursivo" (TRINDADE in PLATÃO, 2008, p. 91). A intelecção dos objetos padece das marcas do tempo o que confere o caráter relativo do processo discursivo [do dito] costurado com os três primeiros momentos. Contudo, também a ciência é tecida com o fio do tempo o que lhe confere validade e valor relativos[ao sujeito que conhece e ao objeto conhecido].

Outro aspecto importante do quarto momento relativo ao todo do processo dialético é o fato de que ele, enquanto inteligência da coisa é o que mais se aproxima da coisa mesma "por parentesco e semelhança". O termo

${ }^{7}$ A afirmação de Gadamer é: "Die Erkentnnis selbst” (GADAMER, 1970, p. 96). 
intelecção expressa muito bem o que se pretende com esse momento e que corresponde ao conhecido Insight.

"no qual subitamente alguma coisa contribui para a inteligibilidade da relação interna da coisa mesma se faz presente a mim de uma vez: os degraus da prova, a construção auxiliar, que foi tão difícil de encontrar e sua função na prova, e assim por diante. Mais do que qualquer outra coisa esta evidência, que faz alguém querer dizer, eu captei isso, contém a relação intrínseca da estrutura matemática ela mesma. Platão chama esta evidência de Nous" (GADAMER, 1970, p. 99).

$\mathrm{O}$ quarto momento da dialética - enquanto Insight, inteligência ou intelecção - é o que mais se aproxima da coisa mesma.

$\mathrm{Na}$ esteira de Heidegger, ainda sobre a marca da facticidade na constituição da ciência [válido para a filosofia], Gadamer afirma que

\begin{abstract}
"Qualquer Insight que podemos possuir emerge em um discurso humano finito e, por isso, apenas parcialmente.[...] Nossos insights, em outras palavras, são marcados por nossa discursividade. O que nos é dado nos é dado do ocultamento [léthe] e em um lapso de tempo de volta a ele. Daí porque nossa verdade humana é a-letheia, jamais é absoluta" (SMITH in GADAMER, 1980, p. 103-104).
\end{abstract}

Os quatro momentos iniciais constituem um conjunto discursivo e, portanto, são falíveis. Gadamer chama atenção ao caráter finito, temporal, limitado desse momento, pois, dependendo da apreensão dos estágios anteriores é possível que alguém seja levado a fazer uma leitura errada da coisa, ou seja, a construir uma ciência não apropriada a ela. Significa também que toda e qualquer forma de conhecimento humano é sempre temporal e, por isso, relativo. Essa advertência constitui uma das importantes contribuições da filosofia hermenêutica - à esteira do existencialismo e da fenomenologia - relativamente à hermenêutica dos textos antigos, à compreensão de ciência e à concepção mais ampla e autêntica de filosofia. $\mathrm{O}$ que nos chama atenção eé muito importante para a compreensão da metodologia e, portanto, da filosofia - tanto platônica quanto hermenêutica 
filosófica - é que Gadamer, ao reler os textos e a filosofia, como um todo, acaba por humanizá-la e historicizá-la.

Encontramos, em Goldschmidt, uma interpretação similar àquela que está espelhada na hermenêutica filosófica. Isso se visualiza na sua resposta à questão: "o que valem os quatro primeiros modos de conhecimento?":

"O nome é estabelecido de modo convencional, arbitrário [...] A definição, composta de nomes e verbos, participa da instabilidade de seus elementos. A imagem concreta é 'cheia de elementos contrários ao quinto'[...]. O quarto modo de conhecimento, a ciência, a inteligência e a opinião verdadeira, também é imperfeito[...] Quer se inscrevam na matéria verbal ou corporal ou na alma, os quatro modos têm em comum o fato de serem exteriores ao objeto. Pode-se solicitar a eles que figurem o objeto, que o representem, que se aproximem dele o mais perto possível, mas jamais que o substituam [...] Neste sentido, os quatro modos de conhecimento são todos ainda que em graus diferentes, 'imagens' e, 'a mais grave' crítica, enquanto procuramos conhecer 'a essência', os quatro modos nos dão a "qualidade"” (GOLDSCHMIDT, 2002, p. 5-6).

Em suma, os quatro primeiros momentos ${ }^{8}$ da dialética apontam ainda apenas para as qualidades das coisas e não para sua essência, ou seja, para aquilo que sacia nossas almas.

Nesta direção ainda, para Trabattoni, "nem o nome do círculo, nem o discurso que o descreve, nem a imagem que o desenha nem mesmo o conhecimento que o sujeito tem de tal coisa, são a mesma coisa que o objeto"

\footnotetext{
${ }^{8}$ Levando em conta que a proposta de Schleiermacher relativa ao tema da interpretação consistiu em elaborar uma ciência hermenêutica - superando a tradição pregressa que não havia pretendido fazer da arte de interpretar uma ciência - pensamos que é possivel sustentar um paralelismo entre os primeiros quatro momentos da dialética cujo ápice é a intelecção da coisa e a 'divinação'. De acordo com Schleiermacher, na articulação e exercício relacional entre o todo e a parte, emerge e efetiva-se a 'divinação', ou seja, o entendimento [o conhecimento propriamente dito] do que é a coisa inquirida [mesmo que, no caso, seja a intenção do autor supostamente contida num texto]. No caso da ciência hermenêutica de Schleiermacher a intelecção, enquanto momento divinatório, consiste na captação da intenção do significado projetado pelo autor num determinado texto por parte de um intérprete. Assim, a divinação, em nossa opinião, equivale ao que convencionamos chamar de intelecção da coisa, a qual, por sua vez, participa do processo da hermenêutica filosófica, mas não se restringe a ele. Por ora basta indicar esta pista com o intuito de marcar o lugar da hermenêutica metodológica bem como justificar o modo filosófico proposto por Gadamer por meio de um paralelismo com o processo dialético desenvolvido por Platão segundo nossa leitura filosófica.
} 
(TRABATTONI, 2003, p. 184). Porém, de acordo com Platão, "se não apreendermos, de um jeito ou de outro, esses quatro elementos, jamais alcançaremos o conhecimento perfeito do quinto" [342e], contudo, "esses elementos pretendem exprimir, com a debilidade irremediável de nossa linguagem, não apenas as qualidades do ser, como também sua essência” [343a].

Os quatro momentos constituem e tramam as condições para alcançar o conhecimento perfeito do quinto. $\mathrm{O}$ alcance desse último ocorrerá apenas se aqueles forem apreendidos num todo e articulados entre si numa perspectiva conjunta e crescente de compreensão da coisa [mesma]. Participam da com-preensão do real à medida que explicitam suas qualidades e apontam sua essência, porém, não revelam ainda a coisa mesma, não permitem possuir seu entendimento total nem sua conceitualização apropriada aos seus contornos porque a linguagem ${ }^{9}$ - o nome, a definição, a imagem e também a ciência dos objetos - é limitada porque somos finitos. Por outro lado, do ponto de vista do objeto - a intelecção da coisa não acaba nem se esgota, pois ela mesma é insondável; do ponto de vista de quem conhece, não é possível apreendê-la totalmente. Em outras palavras, "o quarto [momento] não é um novo elemento, independente e diverso dos três primeiros, mas sim a transferência deles ao lado do sujeito. E é totalmente consequente que a fraqueza do nome, da definição e da imagem comporte também a fraqueza do conhecimento do nome, da definição e da imagem" (TRABATTONI, 2003, p. 187).Apesar disso, ela é o caminho mais apropriado e único [caso contrário, diante do mistério das coisas, deveríamos permanecer mudos], imprescindível, para conhecermos a coisa.

Enfim, levando em conta a imagem da escada, os quatro estágios mencionados representam e possibilitam instaurar a ciência propriamente dita; podemos, porém, jogá-la fora após sua instauração? Do ponto de vista de Platão e de Gadamer conservamo-la conosco sem nos fixarmos aos seus distintos degraus e sem nos determos no quarto momento, pois "hermenêutica e dialética não dispensam [...] os progressos de exploração e

\footnotetext{
${ }^{9}$ No Fedon Platão dedicou-se a essa questão ao introduzir o tema da segunda navegação onde declarou que "o único meio à disposição do homem para superar a incerteza estrutural da percepção sensível (dependente, por sua vez, da mobilidade heracliteana da realidade material) consiste no recurso aos logoi, isto é, a palavras e discursos" (Cf. TRABATTONI, 2003, p. 187-188). Também no Político ele explicitou algo similar. Com isso, em ambos os textos, "o recurso ao logos aparece como o método obrigatório da filosofia, se ela quer ocupar-se de objetos mais nobres do que os materiais" (Cf. TRABATTONI, 2003, p. 188).
} 
medição do objeto que as ciências humanas desenvolvem" (STEIN in HABERMAS, 1987, p. 131) porque as tecem com o fio da facticidade.

\subsubsection{Quinto momento: 0 objeto, a coisa mesma [die Sache]}

Em continuidade aos momentos anteriores, o quinto é "a coisa conhecida e que verdadeiramente existe" [342b] expresso por Platão como sendo "o círculo em si mesmo" [342c]. Ele é distinto dos três momentos e se aproxima "por afinidade e semelhança" [342d] ao quarto. O objeto em si mesmo é compreensível para alguém de modo que ele não pode ser tido como um objeto exterior ao sujeito que o conhece e muito menos como possuindo existência em um mundo separado dele.

A meta do método dialético ascencional consiste em [nos] aproximarmos e atingirmos, de certa maneira, a coisa mesma; a plenitude procurada por ele efetiva-se enquanto uma experiência que realizamos com ela. Pressupondo a intelecção do objeto, o quinto momento consiste na sua intuição filosófica. Para que ocorra esta experiência da coisa mesma são necessárias algumas exigências. A primeira delas reside em saber lidar com os quatro momentos prévios. Além disso,

“o filósofo tem necessidade [...] de algumas qualidades que se poderia, por mais comodidade, dividir em intelectuais e morais. Ele deve ser dotado de uma grande facilidade para aprender e de uma memória poderosa. Exige-se dele ainda um 'vínculo natural com as coisas justas e belas' e 'uma afinidade com o objeto"” (GOLDSCHMIDT, 2002, p. 4).

Não possuímos dificuldade em compreender a primeira exigência relativa aos quatro momentos da dialética, contudo, quanto à segunda exigência, o que significa dizer que o filósofo deve possuir afinidade com $o$ objeto? Embora admitamos que deva haver um vínculo natural com as coisas justas e belas por parte de alguém que estude as virtudes e valores, de acordo com Goldschmidt, Platão "declara de maneira geral: para quem não tem afinidade com o objeto, de nada serviriam nem a facilidade de apreender nem a memória [344a 2-4]” e ao invocar essa 'ligação' ele não está a falar de "uma multiplicidade de objetos de estudo, mas do Objeto simplesmente, da Essência inteira [344a 3 - b 2-3]. Assim, a uma página de intervalo, encontramos uma lista detalhada dos objetos da filosofia e a menção global 
do 'Objeto”' (GOLDSCHMIDT, 2002, p. 4-5). O quinto momento pressupõe, por parte de quem se envereda em sua busca, afinidade com o belo, com o bom, com a verdade. ${ }^{10} \mathrm{O}$ fracasso do tirano de Siracusa deveu-se, entre outras razões, à falta dessa exigência fundamental para o exercício filosófico.

A atualização do quinto momento acontece mediante as exigências apontadas e pode ser melhor compreendida levando em conta as diferentes caracterizações relativas à coisa mesma visada e procurada pela dialética ascendente. Reale caracteriza a coisa mesma, enquanto tema de fundo da Carta Sétima da seguinte maneira:

"a. o inteiro, ou seja, o Todo (to holon, 341a2); b. as coisas maiores (ta megista, 341b1); c. a natureza, ou seja, a realidade em seu fundamento (physis, 341b7); d. o Bem (Agathon, 342d4); e. a verdade na medida do possível da virtude e do vício (aletheia arete eis to dynaton kai kakia, 344a8-9); f. o falso e o verdadeiro de todo o ser (pseudos kay alethes tes holes ousia, 344b2); g. as coisas mais sérias (ta spoudaioteta, $344 c 6$ ); h. os Princípios primeiros e supremos da realidade ( $t a$ peri physeos akra kai prota, 344d4-5)" (REALE in PERINE, 2009, p. 223).

De acordo com Gadamer, Platão, ao fazer uso do círculo [pela facilidade de entendimento e abstração] para explicitar o processo de compreensão filosófica, pretende mostrar que, ao final do processo - embora tenhamos provas, argumentos pelo nome, conceito, imagem, ciência dos objetos - jamais possuiremos a verdade plena relativa à coisa, à ideia; isto é, "ele quer nos mostrar que, de fato, este ideal não pode ser realizado" (GADAMER, 1970, p. 95). Assim,

"a questão não é como alguém comunica seu conhecimento da coisa, mas como a coisa se comunica mesmo - como a coisa é, isto é, que tipo de realidade ela tem quando conhecimento e comunicação tomam lugar. Lógos e epistéme são sempre compreendidos relativamente à coisa [...] A 'coisa' (Sache) é o objeto noético, ou, como Platão diria, a Ideia,

\footnotetext{
${ }^{10}$ De acordo com Platão: "Ora, o divino é belo, sábio e bom e tudo o mais do mesmo gênero, pois é isso o que alimenta e faz crescer as asas da alma", Fedro, 246e.
} 
como aquilo que é verdadeiramente real” (GADAMER, 1970, p. 95-96).

Enquanto que os três primeiros momentos da dialética são facilmente comunicáveis e juntamente com o quarto possibilitam que a coisa conhecida se faça 'presente' a nós, o quinto, “a realidade mesma, o conhecimento do que está em consideração, é distinto de todos eles” (GADAMER, 1970, p. 96). Embora não prescinda dos momentos anteriores, seu modo de acontecer e de explicitar revela a natureza própria da filosofia. Alhures desenvolveremos distintas maneiras para caracterizar o acontecimento de 'apropriação' e de explicitação da coisa mesma. ${ }^{11}$ Enfim, mostramos os distintos momentos do movimento dialético ascendente; vejamos agora o método do método dialético.

\section{Sobre o método do método dialético}

Em consonância com a proposta dialética, justificaremos que seu método deve ser também dialético. Fundamentaremos isso explicitando, inicialmente, a dialética entre seus dois movimentos [descendente e ascendente]; mostraremos, a seguir, que ela se efetiva entre os momentos próprios de cada movimento; e, por fim, sustentaremos que sua uma metodologia é circular espiralar virtuosa.

\subsection{Dialética entre os dois movimentos do método dialético}

Embora seja constitutiva do método dialético a conjunção dialética entre os seus dois movimentos básicos, é comum reduzi-lo ou ao seu itinerário descendente ou caminho ascendente. $\mathrm{Na}$ história da filosofia isso se encontra retratado nas clássicas concepções - ou interpretações - da dialética em sua versão hegeliana [idealista] e marxista [pragmática].

Aqui, ao justificarmos que o método da dialética deve ser dialético, reiteramos que seu escopo primeiro e último é 'atingir' a coisa mesma,

\footnotetext{
11 Trata-se de uma reflexão em construção intitulada "Metáfora e Meta do método dialético ascendente" onde nos propusemos mostrar que o quinto momento se compreende mediante metáforas como aquela da construção de uma casa em comparação à feitura do fogo apresentada pelo próprio Platão. Encontramos outras expressões e metáforas, na tradição filosófica, que revelam o quinto momento da dialética: de modo mais direto, os termos faísca e centelha utilizados por Platão e Epifania por J. Trindade; de maneira indireta, a experiência do Salto elou da Lichtung [Heidegger], a experiência estética [Gadamer] e a metáfora do Fogo de Artificio [Adorno].
} 
porém, a efetivação dessa meta não constitui um estado final e acabado, mas se converte num elo para percorrer o caminho da volta. Nas palavras de Goldschmidt,

\begin{abstract}
"após ser elevada até o princípio último, a investigação deve 'vincular-se a todas as consequências que dele dependem e descer assim até a conclusão última' [...]. Estamos de volta, pois, à ordem discursiva, ao domínio da linguagem em que se movem os quatro modos de conhecimento e, entre eles, a ciência. Mas, consecutiva agora à visão da essência, ela é ciência não mais obscura, mas 'perfeita"' (GOLDSCHMIDT, 2002, p. 8-9).
\end{abstract}

Dito de outro modo, o caminho de saída e o de retorno à caverna institui um elo no qual eles se entrecruzam e instituem uma circularidade [entre os dois caminhos]. Nem a dialética propriamente dita e menos ainda seu método são unidirecionais, segundo a lógica linear progressiva. O método da dialética é tecido pela articulação tensional entre a realidade sensível e a inteligível, entre o plano conceitual e o prático metaforizado pelo movimento cardíaco concomitante da diástole e da sístole.

Pensamos que ambas as faces da dialética - versão inteligí$\mathrm{vel} /$ metafísica e versão prático-dialógica/ética - constituem lados distintos da mesma moeda metodológica e possuem, portanto, finalidade similar. A primeira tem por escopo definir, explicitar possibilitar a realização de uma experiência, por exemplo, do conceito de belo e não apenas construir um conceito sobre ele ao passo que a segunda visa efetivá-la plenamente. $\mathrm{O}$ método dialético - o mesmo se aplica ao modelo estrutural da hermenêutica filosófica - compreende-se enquanto um movimento de subida e de descida concomitante, um caminho que sobe e desce incessantemente e cujos momentos são distinguíveis apenas para efeitos didáticos segundo o pressuposto de que "hermenêutica e dialética representam, de maneira única e privilegiada, o travejamento de um tipo de forma de vida do pensamento que não se descola do mundo e da práxis vivida [...]” (STEIN in HABERMAS, 1987, p. 131).

Do que se disse, podemos extrair alguns corolários: o primeiro é de que, ao lermos os diálogos de Platão, temos a impressão de não sabermos ao certo qual é a direção primeira, em termos cronológicos, do movimento dialético: se a da subida ou a da descida. Talvez a resposta desse dilema esteja 
contida no aforismo de Heráclito: "o caminho para cima e para baixo são um e o mesmo” (HERÁCLITO in GUTHRIE, 1984, p. 417). Com relação à Carta Sétima, vista em seu todo, é possível entrever nela tanto a trilha da descida [revelada no esforço de Platão para pôr em prática a verdadeira filosofia ao modo daquele que retorna à caverna - trata-se da sua proposta ético-política] quanto a senda da subida [composta pelos elogios da verdadeira filosofia e do método dialético ascendente - que configura sua proposta metafísica],desenvolvida na digressão.

Em segundo lugar, ao analisarmos nossas práticas filosóficas, nos damos conta de que percorremos os caminhos de subida e de descida quase que concomitantemente. Ou seja, normalmente, é por causa de uma espécie de dúvida ou insight sobre algum tema ou problema que encetamos o caminho da subida ao nos dedicarmos a estudar a história da filosofia a fim de construirmos um conceito [sobre ele]. Por outro lado, a aquisição de mais clareza e consistência conceitual nos leva a fazer comparações com a realidade e, consequentemente, instaurar uma prática mais filosófica. Porém, os dois movimentos, se pensados com cuidado, são inseparáveis e compreendem-se numa unidade tensional e complementar.

Em terceiro lugar, comumente compreende-se a dialética do ponto de vista ascencional e se esquece que ela se constitui sobre o caminho de volta. A carta nos atesta, de modo bastante claro, que a identidade da filosofia é tecida conjuntamente com as veredas da subida e da descida, do exercício teórico e prático. A dialética e a hermenêutica comungam da noção de filosofia irredutível ao seu aspecto cognitivo [epistemológico] e sustentam que ela deve pautar nosso modo de viver. $O$ processo dialético implica que o conhecimento nos leva a sermos melhores à medida que implica uma transformação pessoal e, portanto, política.

Em quarto lugar, o caminho da dialética ascendente caracteriza-se enquanto um esforço teórico eterno, enquanto durar - mas não metaempírico ou desvinculado da prática -, que culmina, se revela e acontece ao modo de uma faísca, enquanto uma intuição, uma experiência acerca do objeto procurado, o que configura uma noção de metafísica autêntica. Considerando que a metafísica dialética é conjugada pelos movimentos ascendente e descendente, o equívoco de determinados projetos metafísicos residiu em deter-se num deles. Sucumbiu, pois, a metafísica que se pautou ou apenas pelo caminho de subida ou o de descida. Nossa leitura da Carta Sétima possibilita justificar que a coisa mesma só se diz, só se compreende e se manifesta plenamente num movimento 
circular entre os distintos movimentos regidos por aquela ânsia de nos aproximarmos dela, numa dinâmica do ir e vir [a ela] espelhável e similar ao movimento das ondas do mar.

Enfim, segundo nossa proposição, na Carta Sétima, o relato de Platão constitui a explicitação do caminho de volta que implica, necessariamente, o caminho da subida. Nas palavras de Gadamer, a filosofia não se erige apenas sobre o itinerário da palavra ao conceito, mas vai deste àquela. Ousamos até afirmar que, no interior da tradição filosófica, o problema residiu em absolutizar ou o caminho da subida [idealismo filosófico] ou o da descida [realismo filosófico], em detrimento de uma articulação conjunta e coerente entre ambos. O desafio metodológico proposto pela carta é o de conservarmos, tensionalmente, o itinerário ascendente e descendente relativamente aos dois movimentos e aos seus respectivos e distintos momentos. Uma lição importante da interpretação gadameriana de Platão reside justamente em justificar que a filosofia é uma atividade prática que precisa ser costurada concomitantemente com sua face teórica - e vice-versa. Trata-se, pois, de um exercício que conjuga o diálogo entre pessoas e o trabalho solitário e silencioso de compreensão universal do real em colóquios amistosos sem ressaibos de inveja.

\subsection{A dialética interna dos distintos movimentos}

O que se disse acima se aplica aos dois movimentos da dialética, mas também aos seus distintos momentos internos. Retomemos, a propósito disso, a indicação metodológica de Platão:

"Só depois de esfregarmos, por assim dizer, uns nos outros, e
compararmos nomes, definições, visões, sensações [...] é que
brilha sobre cada objeto a luz da sabedoria e da inteligência,
com a tensão máxima de que forem capazes as forças
humanas" [344b 7-9].

Diante disso, percebemos que o movimento lógico interno entre os distintos momentos não é puramente linear progressivo. $O$ exercício de esfregar e comparar nomes, definições, visões e sensações - entre si - trama um caminho que vai e vem entre eles relativo sempre ao Objeto, à coisa mesma. Portanto, o método para compreender e explicitar os distintos momentos do movimento dialético também é dialético. 
A dialética efetiva-se tanto no movimento de subida e de descida aos princípios quanto no próprio movimento ascensional. Esse visa apontar, conduzir e expressar, ainda que parcialmente, a própria coisa e, de 'posse', ainda que parcial, dessa coisa, deve-se fazer o caminho da volta, o que institui um movimento circular.

\title{
3.3. Dialética circular virtuosa
}

Corroboramos a afirmação de Goldschmidt segundo a qual "a enumeração sucessiva do nome, da definição, da imagem, da ciência associada à inteligência e à opinião verdadeira, não representa, por conseguinte, uma ordem hierárquica” (GOLDSCHMIDT, 2002, p. 9). Para justificar isso, ele retoma o trecho da República onde, "para iniciar o estudo das coisas inteligíveis, a alma "é obrigada a servir-se, como de outras tantas imagens, das coisas sensíveis, procedendo a partir de hipóteses" [VI, 510d 45] do que extrai a seguinte conclusão:

\begin{abstract}
"O dialético procede como o geômetra até chegar à hipótesedefinição. Mas, em vez de passar nesse momento imediatamente e sem retorno para as consequências, ele se eleva progressivamente de hipótese em hipótese, até chegar ao 'princípio de tudo', 'ao que há de mais luminoso no ser' - a essência; daí ele somente torna a descer para as conclusões [ciência 'perfeita]'” (GOLDSCHMIDT, 2002, p. 9).
\end{abstract}

Ao geômetra bastaria chegar ao quarto momento, ao filósofo, porém, não. É no exame cuidadoso e caminhando de um momento ao outro "que se gera com muito trabalho no espírito naturalmente capaz a ciência" [Carta Sétima, 343 e 1-3] sendo "provável que em todos os estágios da caminhada dialética reencontremos nomes, definições, imagens, opiniões, a ciência e enfim a inteligência, impaciente para alcançar a Essência” (GOLDSCHMIDT, 2002, p. 10-11). Para efeitos didáticos, convém lembrar as idiossincrasias de cada movimento e momento, porém, no seu interior efetiva-se similar dinâmica, ou seja, em ambos instaura-se um processo circular espiralar. Acontece, pois, uma circularidade virtuosa, tanto entre os distintos movimentos quanto entre seus distintos momentos. Diferentemente da lógica científica experimental progressiva ou do método dedutivo, a 


\begin{abstract}
"progressão natural do movimento dialético poderá sofrer retardamentos, ser obrigada a tomar desvios; ela poderá, em uma palavra, ceder a influências perturbadoras provenientes notadamente dos interlocutores que não apresentariam as qualidades - intelectuais ou morais - necessárias" (GOLDSCHMIDT, 2002, 11).
\end{abstract}

Afirmamos que a dinâmica da dialética ascendente não é apenas linear progressiva, tout court, mas que ela se configura como um movimento circular virtuoso na medida em que não visa apenas confirmar hipóteses ou conhecimentos já existentes - indicativos parciais do círculo vicioso - ao instaurar novas e apropriadas margens do saber sob a égide da lógica trinitária.

$\mathrm{Na}$ dinâmica interna do método dialético conserva-se a linearidade salvaguardando, pois, a importância e a contribuição das ciências - mas incorpora-se nela a circularidade aberta. Não se trata, pois, de uma circularidade viciosa, mas virtuosa porque no seu interior o tempo linear é conjugado com o tempo cíclico (Cf. ROHDEN, 2004), e novas sínteses são sempre possíveis de serem elaboradas porque a vida, o real são dinâmicos. Trata-se de um movimento circular virtuoso porque, tendo a coisa mesma como objeto de sua busca, do ponto de vista teórico [universal] "há um imperceptível avanço", ${ }^{12}$ como diria Rosa, pois uma outra margem é possível de ser instaurada. Daí porque, rigorosamente falando, a dialética circular virtuosa tem, na verdade, um caráter espiralar. Vicioso é aquele movimento que pretende apenas confirmar um pressuposto e comprovar uma hipótese inicial de investigação [restrito, pois, ao particular]. Uma das virtudes da dialética reside em fundamentar o filosofar sobre a dinâmica de ampliação concêntrica crescente de nossos conhecimentos sobre nós mesmos, sobre os objetos e sobre nossa relação com eles e vice-versa, com o escopo de explicitar o que, de fato, é essencial em nosso tempo existencial.

\title{
Indicações conclusivas
}

Enfim, a compreensão, a explicitação e a justificação da dialética enquanto um movimento circular virtuoso ou espiralar permite e possibilita ao filósofo não sucumbir à tentação de se afundar no pragmatismo ou de

12 A formulação completa é: "O mundo se repete mal é porque há um imperceptível avanço" (Cf. GUIMARÃES ROSA, 1976, p. 86). 
ficar enredado no [seu] mundo de ideias [fixas]; além disso, decorre do exercício circular virtuoso a prática filosófica que visa conjugar o bem pensar com o bem viver ${ }^{13}$ [e até o bem escrever] instituindo um padrão conceitual para aferir posturas em sua versão teórica e/ou prática. Nos elogios à verdadeira filosofia da carta de Platão, encontramos indícios ideais graças aos quais se efetiva uma circularidade virtuosa na medida em que procura perceber e encontrar o que é essencial no correr do movimento temporal, cujos frutos próprios são a temperança, a confiança, a amizade e a justiça. A ideia, pois, se faz carne e passa a reger nossas vidas na medida em que a dialética nos possibilita apreender o essencial enquanto um ideal a ser concretizado em cada movimento temporal - o que se efetiva de modo circular espiralar.

$\mathrm{Na}$ escritura da Carta Sétima, é possível apreender o movimento da dialética descendente em sua vertente dialógica pela proposição ético-política de Platão, visível em suas viagens a Siracusa; por outro lado, na sua digressão encontra-se estruturada a dialética ascendente em sua versão inteligível, ou seja, metafísica. No bojo de ambos os movimentos instaura-se o itinerário de subida e de descida concomitante porque jamais possuiremos uma apreensão definitiva do objeto. Ou seja, a dialética é dialética porque somos seres históricos, dotados de liberdade enquanto que o real [ou a ideia, ou o ser] como nossa alma - não tem contornos e bordas definidas. A finitude de um e a inesgotabilidade do outro implicam, necessariamente, uma dinâmica bem como uma compreensão e explicitação dialética. Desse modo, o método filosófico não é exterior ao sujeito nem ao objeto investigado. O que importa, filosoficamente falando, é o percurso a ser feito por quem se envereda no caminho de compreensão do que é essencial. É por isso que o que importa é a relação compreensiva mesma de ampliação concêntrica entre a coisa e nossa apreensão dela representável no caminho de subida e de descida aos princípios metaforizada pela existência mítica do deus Hermes ou pelo aforismo heracliteano caminho: para cima e para baixo, um e o mesmo.

Filosofar com Platão e Gadamer significa tomar consciência do nosso tempo e procurar explicitá-lo segundo uma determinada lógica, no caso, a dialética. Para além de historiografia tout court de seus textos, nos propusemos justificar que a realidade e sua apreensão expressam-se de modo apropriado segundo a dinâmica dos dois movimentos, dos momentos

\footnotetext{
${ }^{13}$ Inspiração no lema isocrático: "aprender a falar bem é aprender a viver bem".
} 
internos e do método [dialético] da dialética. Sem renunciar ao caminho de progressão do conhecimento relativo ao objeto, a proposta dialética não se reduz ao itinerário linear ascencional, mas assenta-se sobre o chão da finitude e explicita-se circularmente. Ora, além do incessante esforço individual para compreendermos a coisa mesma, precisamos aprender a discutir nesses colóquios amistosos em que questões e respostas se formulam sem o menor ressaibo de inveja.

\section{Referências Bibliográficas}

GADAMER, H-G. "Da palavra ao conceito. A tarefa da hermenêutica enquanto filosofia”. In: ALMEIDA, C. L. da S; FLICKINGER, H-G.; ROHDEN, L. (orgs.). Hermenêutica filosófica - nas trilhas de Hans-Georg Gadamer. Porto Alegre: Edipucrs, 2000. p. 13-26.

. "Dialectic and Sophism in Plato's Seventh Letter". In: GADAMER, H-G. Dialogue and Dialectic; eight hermeneutical studies on Plato (Trans. and with an introduction by P. Christopher Smith). Binghamton, NY: Yale University, 1980. pp. 91-123.

. "Dialektik und Sophistik im siebentem Platonishen Brief (1970)". In: Gesammelte Werke. V. 6 - Griechische Philosophie. Tübingen: J.C.B. Mohr (Paul Siebeck), 1985. p. 90-115.

GOLDSCHMIDT, Victor. Os diálogos de Platão. Estrutura e método dialético. São Paulo: Ed. Loyola, 2002.

HERÁCLITO, Fragamentos. Origem do pensamento (Ed. Bilíngue com tradução, introdução e notas de Emmanuel Carneiro Leão). Rio de Janeiro: Tempo Brasileiro, 1980.

PLATÃO. Carta VII (Trad. do grego e notas de José Trindade Santos e Juvino Maia Jr). Rio de Janeiro, São Paulo:: Ed. Puc-Rio; Loyola, 2008.

REALE, G. "A grande importância da Carta Sétima para o pensamento de Platão”. In: PERINE, M. (Org.). Estudos Platônicos. Sobre o ser e o aparecer, o belo e o bem. São Paulo: Loyola, 2009. p. 211-224.

ROHDEN, L. "Filosofia enquanto Fenomenologia e Hermenêutica à luz da Carta Sétima de Platão". In: BOMBASSARO, L. C.; DALBOSCO, C. A.; KUIAVA, E. A. (orgs.). Pensar Sensível. Caxias do Sul: Educs, 2011. p. 87-104. "Hermenêutica metodológica e hermenêutica filosófica". In: Interfaces da Hermenêutica: método, ética e literatura. Caxias do Sul: Editora UCS, 2008, v.1. p. 35-57.

"Hermeneutik: kritische Wiederaufnahme der Metaphysik mittels 
der Zeit”. In: Metaphysik und Hermeneutik. Kassel: Unidruckerei der Universität Kassel, v. 38, 2004, p. 142-154.

ROSA, J. G. Tutameia. 4.ed. Rio de Janeiro: José Olympio Editora, 1976.

STEIN, E. "Apêndice - Dialética e Hermenêutica: uma controvérsia sobre método em filosofia”. In: HABERMAS, J. Dialética e Hermenêutica. (Trad. Álvaro Valls). Porto Alegre: L\&PM, 1987. p. 98-134.

TRABATTONI, F. Oralidade e escrita em Platão (Trad. Roberto Bolzani Filho, Fernando Eduardo de Barros Rey Puente. São Paulo, Ilhéus: Discurso Editorial, Editus, 2003.

E-MAIL: rohden@unisinos.br

RECEBIDO: Setembro/2012 APROVADO: Novembro/2012 